\title{
Analisis Pemanfaatan (Learning Management System) Google Classroom sebagai Media Digitalisasi Pembelajaran Jarak Jauh di Era Pandemi Covid 19
}

\author{
Indah Dwijayanthi Nirmala ${ }^{1,{ }^{*}}$, Dwi Budi Srisulistiowati ${ }^{1}$, Sri Rejeki ${ }^{1}$ \\ 1 Informatika; Universitas Bhayangkara Jakarta Raya; Jl Raya Perjuangan No. 81 Bekasi Utara, \\ (021) 889558822; e-mail: indah.dwijayanthi@dsn.ubharajaya.ac.id, \\ dwibudi@dsn.ubharajaya.ac.id, sri.rejeki@dsn.ubharajaya.ac.id \\ * Korespondensi: e-mail: indah.dwijayanthi@dsn.ubharajaya.ac.id
}

Diterima: 14 Des 2020 ; Review: 21 Des 2020; Disetujui: 30 Des 2020; Diterbitkan: 31 Des 2020

\begin{abstract}
Electronic learning (E-learning) is essentially an educational learning medium through the use of computer or internet technology, namely web-based learning technology (Web Based Instuction). the implementation of e-learning is one part of alternative technology in helping to run the learning curriculum during the Covid 19 pandemic. aimed at knowing the process of implementing LMS learning with google classroom II-B material class, to find out the perceptions of teachers and students towards the implementation of the COVID 19 pandemic era google classroom learning. This research uses a qualitative method approach, the data sources in this study include primary and secondary data sources. Data collection techniques using the method of observation, interviews, and documentation. Analysis of the data in this study using data analysis flow model "Miles and Huberman". Checking the validity of the data using credibility, transferbility, dependability, and confirmability.
\end{abstract}

Keywords: Elearning, LMS, Google Classroom, Pandemic, Covid 19

\begin{abstract}
Abstrak
Electronic learning (E-learning) pada hakikatnya merupakan media pembelajaran pendidikan melalui pemanfaatan teknologi komputer atau internet yaitu Teknologi pembelajaran berbasis web (Web Based Instuction). Adanya implementasi e-learning menjadi salah satu bagian teknologi alternatif dalam membantu berjalannya kurikulum pembelajaran secara during di masa pandemi covid 19. Penelitian ini ditujukan untuk mengetahui proses pelaksanaan pembelajaran LMS dengan google classroom materi kelas II-B, untuk mengetahui persepsi guru dan siswa terhadap pelaksanaan pembelajaran google classroom era pandemi COVID 19. Penelitian ini menggunakan metode pendekatan kualitatif, sumber data dalam penelitian ini meliputi sumber data primer dan sekunder. Teknik pengumpulan data menggunakan metode observasi, wawancara, dan dokumentasi. Analisis data dalam penelitian ini menggunakan analisis data model alir "Miles dan Huberman". Pengecekan keabsahan data dengan credibility (keterpercayaan), transferbility (keteralihan), dependanility (ketergantungan), dan confirmability (kepastian).
\end{abstract}

Kata kunci: E-learning,LMS, Google Classroom, Pandemi, Covid 19 


\section{Pendahuluan}

Pelaksanaan pembelajaran adalah proses yang diatur sedemikian rupa menurut langkah-langkah tertentu agar pelaksanaan mencapai hasil yang diharapkan. (Wikipedia bahasa Indonesia, 2020)

LMS adalah aplikasi perangkat lunak untuk kegiatan online, program pembelajaran elektronik (e-learning program) dan isi pelatihan. (Agung Tri Wibowo, Isa Akhlis, Sunyoto Eko Nugroho, 2014)

Electronic learning (E-learning) pada hakikatnya adalah sebagai media pembelajaran pendidikan melalui pemanfaatan teknologi komputer atau internet. (Udin Syaefudin Sa'ud, 2010)

E-learning merupakan sistem pendidikan yang menggunakan aplikasi elektronik untuk mendukung pengembangan kegiatan belaja mengajar dengan media internet, intranet atau media komputer yang lain, dengan adanya e-learning memungkinkan terjadinya proses pendidikan tanpa melalui tatap muka langsung dan pengembangan ilmu pengetahuan kepada pelajar dan mahasiswa bisa dilakukan dengan mudah. (Handani et al., 2016)

Teknologi Informasi dan Komunikasi atau yang lebih dikenal dengan istilah sebagai berikut: information, communication, and teknologi (ICT) mendorong para pembuat keputusan untuk mencantumkan muatan TIK ke dalam kurikulum. (Isnaini et al., 2015)

Aplikasi google classroom memiliki fitur yang mendukung proses pembelajaran eLearning dan dapat digunakan oleh guru selama proses pembelajaran. (Iskandar, 2020)

Salah satu masalah yang dihadapi dunia pendidikan saat ini adalah dampak pandemic COVID-19 yang kini mulai merambah ke dunia pendidikan, sehingga pemerintah berupaya untuk meliburkan seluruh lembaga pendidikan. selain itu pemerintah juga membatasi aktivitas manusia di luar rumah upaya membatasi interaksi antar banyak orang hal itu bertujuan untuk memutus mata rantai penyebaran COVID-19. Kebijakan tersebut tidak hanya berlaku di negara Indonesia saja, tetapi juga di negara-negara yang telah terpapar COVID-19.

Dengan adanya kebijakan tersebut maka sekolah menerapakan kegiatan belajar mengajar dari jarak jauh atau pembelajaran daring (dalam jaringan). Pelaksanaan proses pembelajaran jarak jauh era pandemic COVID-19 ini guru dituntut untuk memilih dan menggunakan metode yang tepat agar proses belajar mengajar tetap berlangsung dengan kata lain terciptalah interaksi edukatif.

Berdasarkan permasalahan yang ada di Sekolah Dasar Negeri Rawajati 08 masih kesulitan menjalankan kegiatan belajar mengajar secara online dalam kondisi pandemi covid 19. Apalagi wabah covid 19 ini belum bisa dikendalikan dan diatasi. Sehingga, potensi penularan dan penyebaran masih tinggi yang akhirnya diputuskannya oleh pemerintah untuk 
seluruh kegiatan belajar mengajar masih harus berjalan diadakan secara during. Maka dari itu, adanya implementasi e-learning dalam memanfaatkan google classroom menjadi salah satu bagian teknologi alternatif dalam kurikulum pembelajaran secara during. Penelitian ini ditujukan untuk mengimplementasikan elearning kurikulum pembelajaran di SDN Rawajati 08, Subjek pada penelitian ini beberapa siswa didik kelas IIB di sekolah tersebut.

\section{Metode Penelitian}

Metode penelitian menurut (Sunyoto, 2016) adalah sebagai berikut: Metode penelitian adalah tatacara bagaimana suatu penelitian dilaksanakan.

Menjelaskan kronologis penelitian, termasuk desain penelitian, prosedur penelitian (dalam bentuk algoritma, Pseudocode atau lainnya), bagaimana untuk menguji dan akuisisi data. Deskripsi dari program penelitian harus didukung referensi, sehingga penjelasan tersebut dapat diterima secara ilmiah. (Herlawati et al., 2018)

\subsection{Tempat dan Waktu Penelitian}

Penelitian ini dilakukan pada bulan november - januari 2021 karena pelaksanaan penelitiannya ini di tengah kondisi pandemi COVID19, pelaksanaan penelitian dilakukan dengan komunikasi secara during yaitu menggunakan media whatsapp, aplikasi google meet untuk berdiskusi dan tanya jawab serta untuk komunikasi bahan informasi dalam pembelajaran jarak jauh dengan menggunakan media google classroom.

Penelitian ini menggunakan pendekatan kualitatif, sumber data dalam penelitian ini meliputi sumber data primer dan sekunder.

\subsection{Metode Pengumpulan Data}

Dalam penelitian ini peneliti melakukan teknik pengumpulan data sebagai berikut:

\section{a. Wawancara dan Observasi}

Adapun observasi yang dilakukan adalah dengan mewawancarai guru dan siswa didik dikarenakan kondisi pelaksanaan kegiatan penelitian ini saat kondisi sedang pandemi COVID 19, maka pada tahap ini melakukan interview / wawancara online menggunakan WhatsApp dan Googgle Meet. Sedangkan observasi pembelajaran google classroom dilaksanakan melalui aplikasi google classroom.

Dalam penelitian menggunakan observasi partisipan, dimana peneliti ikut serta dalam pembelajaran google classroom dan mengamati siswa dan guru selama proses pembelajaran dari awal sampai akhir pembelajaran kemudian hasil observasi ditulis dalam bentuk catatan lapangan. 


\section{b. Dokumentasi}

Dalam penelitian ini peneliti menggunakan dokumentasi yang didapat dari pihak sekolah dan foto-foto yang berkaitan dengan pelaksanaan pembelajaran google classroom era pandemic COVID-19 seperti foto kegiatan pembelajaran.

\section{c. Analisis Data}

Analisis data adalah supaya yang dilakukan dengan jalan bekerja dengan data, mengorganisasikan data, memilah-milahnya menjadi satuan yang dapat dikelola, mensintetiskannya, mencari dan menentukan pola, menemukan apa yang penting dan apa yang dipelajari, dan memutuskan apa yang diceritakan kepada orang lain. (Lexy J. Moleong, 2013)

Analisis data dalam penelitian ini menggunakan analisis data model alir "Miles dan Huberman". (Prof. Dr. Sugiyono, 2016)

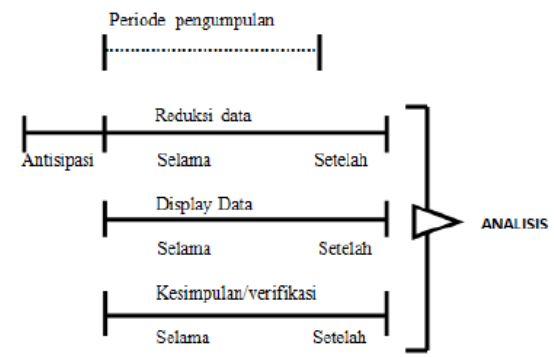

Sumber: Hasil Penelitian (2016)

Gambar. 1. Komponen Analisis Data (Flow Model)

Tabel 1 Units for Magnetics Properties

\begin{tabular}{ccc}
\hline Symbol & Quantity & Conversion from Gaussian and CGS EMU to SI \\
\hline$\Phi$ & magnetic flux & $1 \mathrm{Mx} \rightarrow 10^{-8} \mathrm{~Wb}=10^{-8} \mathrm{~V} \cdot \mathrm{s}$ \\
\hline$B$ & Magnetic flux density, magnetic induction & $1 \mathrm{G} \rightarrow 10^{-4} \mathrm{~T}=10^{-4} \mathrm{~Wb} / \mathrm{m}^{2}$ \\
\hline$J$ & magnetic polarization & $1 \mathrm{erg} /\left(\mathrm{G} \cdot \mathrm{cm}^{3}\right)=1 \mathrm{emu} / \mathrm{cm}^{3} \rightarrow 4 \pi \times 10^{-4} \mathrm{~T}$ \\
\hline$\chi, \kappa$ & susceptibility & $1 \rightarrow 4 \pi$ \\
\hline$\chi_{\rho}$ & mass susceptibility & $1 \mathrm{~cm}^{3} / \mathrm{g} \rightarrow 4 \pi \times 10^{-3} \mathrm{~m}^{3} / \mathrm{kg}$ \\
\hline$\mu$ & permeability & $1 \rightarrow 4 \pi \times 10^{-7} \mathrm{H} / \mathrm{m}=4 \pi \times 10^{-7} \mathrm{~Wb} /(\mathrm{A} \cdot \mathrm{m})$ \\
\hline
\end{tabular}

Sumber: Hasil Penelitian (2016) 


\section{Hasil dan Pembahasan}

Pada bagian ini, dijelaskan hasil penelitian dan pada saat yang sama diberikan pembahasan yang komprehensif. Hasil dapat disajikan dalam angka, grafik, tabel dan lain-lain yang membuat pembaca memahami dengan mudah. Pembahasan dapat dibuat dalam beberapa sub-bab.

Berikut paparan hasil analisis data dalam penelitian yang berjudul "Analisis Pemanfaatan ((LMS) Google Classroom sebagai Media Digitalisasi Pembelajaran Jarak Jauh di Era Pandemi COVID 19" sebagai berikut:

\section{Hasil Wawancara dan Observasi Penelitian}

a. Proses Pembelajaran LMS dengan Google Classroom era Pandemi COVID 19

Dalam pelaksanaan penelitiannya dilakukan dengan obeservasi kegiatan pembelajaran menggunakan google classroom dan wawancara dengan wali kelas II B, dan siswa didik.

Ada beberapa komponen pembelajaran yang diterapkan di sekolah tersebut, yakni: tujuan pembelajaran, materi pembelajaran, media pembelajaran, metode pembelajaran, strategi mengajar, dan evaluasi penilaian dari semua komponen ketercapaiannya dalam pelaksanaan pembelajaran pada materi kelas II-B.

b. Persepsi Siswa didik terhadap pelaksanaan pembelajaran LMS dengan Google Classroom era Pandemi COVID 19

Berikut paparan dari persepsi siswa terhadap pembelajaran google classroom era pandemic COVID-19 dari hasil wawancara, yakni ada beberapa komponen pembelajaran yang diterapkan peneliti, yakni: Materi Pembelajaran, Media Pembelajaran, Faktor Pendukung, Faktor Penghambat, Kelebihan dan Kekurangan

c. Persepsi Guru terhadap pelaksanaan pembelajaran LMS dengan Google Classroom era Pandemi COVID 19

Berikut paparan dari persepsi guru terhadap pembelajaran google classroom era pandemic COVID-19 dari hasil wawancara, yakni ada beberapa komponen pembelajaran yang diterapkan peneliti, yakni: Materi Pembelajaran, Media Pembelajaran, Metode Pembelajaran, Strategi, Faktor Pendukung, Faktor Penghambat, Kelebihan, Kekurangan, Materi Pendukung, serta Penilaian.

\section{Hasil Analisis Data}


Adapun hasil yang diperoleh dari analisis dalam pelaksanaan pembelajaran google classroom era pandemic COVID-19 pada siswa kelas II-B SDN Rawajati 08 Pagi Tahun Pelajaran 2020/2021.

\section{a. Proses Pembelajaran LMS dengan Google Classroom era Pandemi COVID 19}

1) Tujuan Pembelajaran

Tujuan pembelajaran materi kelas II-B ini agar siswa mampu mendeskripsikan, dan mengamati materi ajar yang telah diberikan oleh wali kelas. Berdasarkan hasil observasi materi yang disampaikan guru / wali kelas II-B ini sudah sesuai dengan indikator.

\section{2) Materi Pelajaran}

Karena KBM menggunakan google classroom saat menyampaikan materi guru memeberikan materi yang lebih rinci sehingga dapat membantu memudahkan siswa untuk memahami materi pembelajaran.

\section{3) Media Pembelajaran}

Media pembelajaran yang digunakan dengan media teks, gambar serta video dalam membantu untuk memudahkan siswa didik dalam memahami materi pembelajaran, berdasarkan hasil observasi setiap indikator dari materi pembelajaran guru tidak lepas dalam memberikan contoh gambar ataupun video dengan demikian dapat memperoleh perhatian siswa, karena siswa menjadi lebih aktif selama proses pembelajaran berlangsung.

\section{4) Metode Pembelajaran}

Selama proses pembelajaran, metode tanya jawab ini disesuaikan dengan materi yang disampaikan, keadaan, dan situasi pada pelaksanaan pembelajaran berlangsung. Kondisi selama proses pembelajaran during ini siswa belum terlalu aktif, hanya sekitar $50 \%$ siswa yang aktif, sedangkan $50 \%$ siswa hanya meyimak materi yang disampaikan guru.

\section{5) Strategi Mengajar}

Strategi guru dalam menyampaikan materi kepada siswa yaitu dengan menyampaikan materi yang tidak terlalu banyak artinya materi tidak langsung diberikan kepada siswa secara keseluruhan, akan tetapi dari materi yang dasar ke materi yang kompleks, dan guru memberi waktu kepada siswa untuk membaca dan memahami isi materi kemudian materi tersebut dilengkapi dengan media berupa gambar hal itu menujukkan terciptanya pembelajaran. 


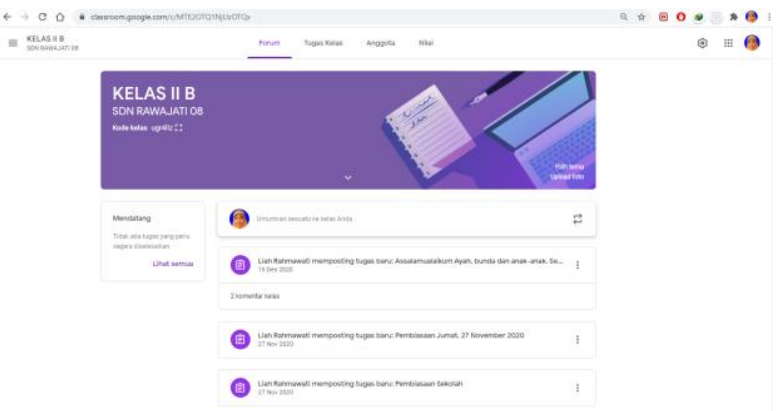

Sumber: Hasil Penelitian (2020)

Gambar 2. Strategi Mengajar Google Classroom

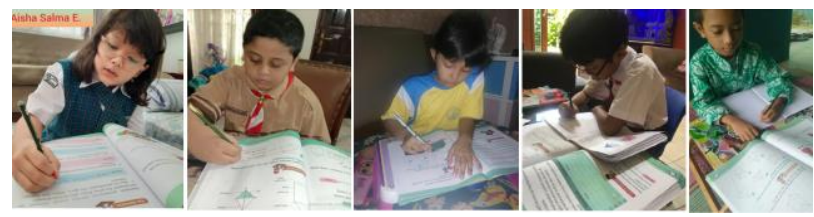

Sumber: Hasil Penelitian (2020)

Gambar 3. Strategi Mengajar di Rumah

Strategi guru dalam pelaksanaan pembelajaran ditunjukkan dari data yang dikemukakan oleh WK dan mengacu pada gambar 4.6 bahwa dalam pembelajaran google classroom guru menyampaikan poin-poin penting disertai dengan media yang mendukung materi seperti penyajian gambar hal itu untuk memvisualisasikan materi tata surya sehingga pembelajaran akan lebih bermakna karena siswa memperoleh gambaran secara langsung.

\section{6) Penilaian}

Penilaian hasil belajar dilaksanakan untuk mengetahui tingkat pemahaman siswa dan mengukur kemampuan siswa dalam memahami materi. Dalam pembelajaran google classroom materi ajar kelas II-B ini dapat diketahui dari 32 siswa yang berhasil mencapai KKM (Kriteria Ketuntasan Minimal) dengan perolehan nilai $\geq 86$ adalah 25 orang sedangkan yang belum mencapai KKM sebanyak 7 orang. Dengan Kriteria Ketuntasan Minimal (KKM) pada siswa kelas II-B SDN Rawajati 08 Pagi tahun pelajaran 2020/2021 adalah $\geq 86$.

Indikator keberhasilan klasikal yang dirumuskan adalah hasil belajar siswa dikatakan berhasil apabila mencapai 85\% dari nilai Kriteria Ketuntasan Minimal (KKM) yang ditentukan sekolah dan KKM mata pelajaran yang bersangkutan.

(Nirmala et al., 2020) 
Patokan pembelajaran dinyatakan berhasil secara klasikal apabila dari total 32 siswa minimal $85 \%$ mencapai KKM. Dari 32 siswa yang mencapai KKM hanya $78 \%$.

Sehingga dapat disimpulkan bahwa pembelajaran google classroom belum berhasil mencapai KKM, tujuan pembelajaran belum tercapai, pembelajaran google classroom ini hanya sebagai alternatif dalam keadaan darurat era pandemic COVID-19.

\section{b. Persepsi Siswa terhadap Pelaksanaan Pembelajaran LMS dengan Google Classroom era Pandemi COVID 19}

1) Materi Pembelajaran

Pembelajaran dengan google classroom di era pandemic COVID-19 materi kelas II-B tetap bisa berjalan dengan baik, dan menarik perhatian siswa dengan memberikan suasana belajar yang berbeda dengan tetap bisa memberikan materi secara terperinci.

Materi Kelas II-B merupakan materi yang menarik, siswa mendapat suasana belajar yang berbeda dari sebelumnya. Kemudian siswa juga merasa nyaman ketika belajar dirumah.

\section{2) Media Pembelajaran}

Siswa didik bisa lebih cepat memahami materi ajar karena guru menggunakan media LMS dengan multimedia berupa teks, gambar, animasi, suara maupun video sehingga media pembelajaran LMS dengan Google Classroom bisa menarik perhatian siswa didik.

\section{3) Faktor Pendukung}

Berikut faktor pendukung dalam pembelajaran google classroom era pandemi COVID-19, yakni:

- Dengan menggunakan google classroom menjadi hal yang baru dan berbeda bagi siswa sehingga rasa keingintahuan membuat siswa tertarik.

- Penyampaian materi yang menarik dengan mendukung media multimedia yang diberikan dan disampaikan guru kepada siswa didiknya dalam kegiatan belajar mengajar secara during/online.

- Strategi Guru yang inovasi dan menarik dalam melakukan pengajaran kepada siswa didik 
- Motivasi dalam diri siswa untuk berkeinginan menggali pengetahuan serta adanya bimbingan langsung yang diberikan oleh wali murid (orang tua) agar siswa dapat mengikuti proses pembelajaran dengan baik.

\section{4) Faktor Penghambat}

Berikut faktor penghambat dalam pembelajaran google classroom era pandemi COVID-19, yakni:

- Kurangnya manajemen waktu

Berdasarkan hasil observasi masih ada siswa yang terlambat dalam mengikuti kegiatan pembelajaran, seharusnya siswa bisa mengoptimalkan waktu kegiatan belajar dengan mengatur jadwal terstruktur mandiri agar lebih disiplin dalam kegiatan belajar mengajarnya.

- Adanya gangguan sekitar

Berdasarkan hasil observasi banyak siswa yang kurang atau tidak bisa fokus dalam pembelajaran karena adanya ganguan dari faktor eksternal seperti keadaan rumah yang tidak kondusif. Hal itu bisa dioptimalkan dengan siswa mencari tempat belajar yang lebih kondusif dan strategis agar bisa konsentrasi saat kbm berlangsung.

- Kendala dengan akses internet

Dengan kendala akses internet menjadi bagian faktor penghambat juga, solusinya bisa siswa didik bisa mencari operator internet yang bagus serta jaringannya stabil seluruh indonesia agar meminimalisir kendala akses internet seperti jaringan jelek, tidak stabil.

\section{5) Kelebihan}

Berikut kelebihan dalam pembelajaran google classroom era pandemi COVID 19, yakni:

- Pembelajaran dengan google classroom sangat efektif. Siswa bisa menerima dengan baik, dpat mengerjakan tugas dengan google classroom, siswa juga bisa belajar dimanapun dan kapanpun dari jarak jauh, sehingga lebih efisien dalam hal waktu serta biaya yang harus dikeluarkan.

- Pembelajaran google classroom dapat menarik perhatian siswa karena memberikan suasana belajar yang baru dan berbeda yakni dengan bantuan akses media internet dengan menggunakan hp maupun komputer/laptop. 
- Pembelajaran google classroom memiliki fitur yang lengkap dan bagus serta terintegrasi dengan email aktif yang dapat dimanfaatkan untuk memudahkan dalam mendapatkan informasi data dan membackup data.

\section{6) Kekurangan}

Untuk kekurangan dalam pembelajaran google classroom era pandemi COVID 19 ini karena tidak adanya praktikum secara langsung sehingga membuat kurang sempurnanya kegiatan pembelajaran secara online ini.

\section{c. Persepsi Guru terhadap Pelaksanaan Pembelajaran LMS dengan Google Classroom era Pandemi COVID 19}

1) Materi Pembelajaran

Materi Pembelajaran yang diberikan guru tidak hanya berupa teks, melainkan gambar yang mendukung maupun video agar dapat menarik perhatian siswa didik dalam mendapatkan materi pembelajarannya.

Sehingga Pembelajaran dengan google classroom di era pandemic COVID-19 materi kelas II-B tetap bisa berjalan dengan baik, dan menarik perhatian siswa dengan memberikan suasana belajar yang berbeda dengan tetap bisa memberikan materi secara terperinci.

\section{2) Media Pembelajaran}

Guru telah menggunakan media LMS dan group whatsapp kelas dengan multimedia berupa teks, gambar, animasi, suara maupun video. Sehingga Siswa didik tertarik dalam kbm during tersebut, dan juga bisa lebih cepat memahami materi ajar.

\section{3) Penilaian}

Persepsi guru terhadap hasil evaluasi pembelajaran pada materi kelas II-B masih rendah, karena siswa didik belum terbiasa menggunakan media online dan mengerjakan kegiatan pembelajaran materi maupun tugas seperti ini sebelumnya, dan selain itu juga ada kendala dari beberapa siswa yang juga terlambat atau tidak mengikuti pembelajaran yang baik dengan waktu yang ditentukan karena terkendala dengan akses internet. Dari salah satu faktor penghambat tadi sehingga perlu diberikan evaluasi susulan kepada siswa yang mengalami kendala tersebut.

Selain itu juga pemahaman siswa terhadap materi masih minim. Kurangnya dirasakan praktek langsung dalam penyampaian materi, karena pelaksanaan kegiatan kbm yang dilakukan secara during/online. 


\section{4) Metode Pembelajaran}

Berdasarkan hasil observasi, guru telah menyampaikan pembelajaran secara during dengan menggunakan forum diskusi via pesan whastapp, google classroom, maupun via telepon. Persepsi guru terhadap metode pembelajaran dengan tanya jawab, masih sedikit siswa yang aktif dari kelas II yang berjumlah 32 anak yang aktif hanya $50 \%$. Sejauh ini berdasarkan hasil observasi siswa memang tidak terlalu aktif pada saat proses pembelajaran berlangsung.

\section{5) Strategi}

Sejauh ini berdasarkan hasil observasi, guru menggunakan media google classroom, serta membuat group whatsapp kelas untuk komunikasi lebih intens nya dalam perkembangan di masa pembelajaran kelas tersebut.

Strategi guru dalam menyampaikan materi kepada siswa yaitu dengan menyampaikan materi yang tidak terlalu banyak artinya materi tidak langsung diberikan kepada siswa secara keseluruhan, akan tetapi dari materi yang dasar ke materi yang kompleks, dan guru memberi waktu kepada siswa untuk membaca dan memahami isi materi kemudian materi tersebut dilengkapi dengan media berupa gambar hal itu menujukkan terciptanya pembelajaran.

\section{6) Faktor Pendukung}

Berikut faktor pendukung dalam pembelajaran google classroom era pandemi COVID-19, yakni:

- Dalam berinteraksi menggunakan media internet dengan google classroom dalam kbm menjadi hal yang baru dan berbeda bagi siswa sehingga rasa keingintahuan membuat siswa sangat menyukai, tertarik dan memberikan rensponsif secara baik.

- Materi yang mendukung dengan media multimedia yang diberikan dan disampaikan guru kepada siswa didiknya.

- Strategi Guru yang inovasi dan menarik dalam melakukan pengajaran kepada siswa didik serta strategi guru dalam menjaga hubungan komunikasi untuk saling berinteraksi dan berhubungan baik kepada wali kelas, guru mata pelajaran, siswa dan wali murid agar meminimalisir miss komunikasi.

- Motivasi dalam diri siswa untuk berkeinginan menggali pengetahuan serta adanya bimbingan langsung yang diberikan oleh wali murid (orang tua) agar siswa dapat mengikuti proses pembelajaran dengan baik. 


\section{7) Faktor Penghambat}

Berikut faktor penghambat dalam pembelajaran google classroom era pandemi COVID-19, yakni:

- Kurangnya manajemen waktu

Berdasarkan hasil observasi masih ada siswa yang terlambat dalam mengikuti kegiatan pembelajaran, seharusnya siswa bisa mengoptimalkan waktu kegiatan belajar dengan mengatur jadwal terstruktur dan lebih disiplin.

- Adanya gangguan sekitar

Berdasarkan hasil observasi banyak siswa yang kurang atau tidak bisa fokus dalam pembelajaran karena adanya ganguan dari faktor eksternal seperti keadaan rumah yang tidak kondusif. Hal itu bisa dioptimalkan dengan siswa mencari tempat belajar yang lebih kondusif.

- Kendala dengan akses internet

Dengan kendala akses internet menjadi bagian faktor penghambat juga, solusinya bisa memilih operator bagus yang memadai untuk bisa akses ke banyak tempat termasuk kawasan terpencilpun sehingga dapat memancarkan sinyal jaringan yang stabil.

\section{8) Kelebihan}

Berikut kelebihan dalam pembelajaran google classroom era pandemi COVID 19, yakni:

- Pembelajaran dengan google classroom sangat efektif. Siswa bisa menerima dengan baik, dpat mengerjakan tugas dengan google classroom, siswa juga bisa belajar dimanapun dan kapanpun dari jarak jauh, sehingga lebih efisien dalam hal waktu serta biaya yang harus dikeluarkan.

- Pembelajaran dengan google classroom dapat menarik perhatian siswa karena memberikan suasana belajar yang baru dan berbeda yakni dengan bantuan akses media internet dengan menggunakan hp maupun komputer/laptop.

- Pembelajaran dengan google classroom memiliki fitur yang lengkap dan bagus serta terintegrasi dengan email aktif yang dapat dimanfaatkan untuk memudahkan dalam mendapatkan informasi data dan membackup data. 


\section{9) Kekurangan}

Untuk kekurangan dalam pembelajaran google classroom era pandemi COVID 19 ini karena kurangnya dirasakan praktek secara langsung dalam penyampaian materi, karena kegiatan pembelajaran dilaksanakan secara during. Sehingga adanya sebagian siswa yang merasa kesulitan untuk mendapatkan pemahaman secara langsung. Dan akhirnya yang dirasakan menjadi kurang sempurnanya kegiatan pembelajaran online ini.

\section{Kesimpulan}

Berdasarkan hasil penelitian yang telah dilakukan, dapat diambil beberapa kesimpulan sebagai berikut

1. Pembelajaran google classroom era pandemi COVID-19 materi $x$ kelas II SDN Rawajati 08 pagi meliputi beberapa komponen pembelajaran, yakni:

a. Tujuan pembelajaran materi kelas II-B ini agar siswa mampu mendeskripsikan komponen tata surya

b. materi pelajaran: guru memberikan materi dengan rinci,

c. media yang digunakan guru berupa teks dokumen, gambar, serta video maupun suara

d. metode yang digunakan metode tanya jawab,

e. strategi mengajar guru dengan menyampaikan poin-poin penting,

f. hasil penilaian pembelajaran google classroom belum berhasil mencapai KKM secara klasikal

2. Persepsi siswa terhadap pelaksanaan pembelajaran google classroom era pandemic COVID-19 materi $x$ yaitu:

a. materi tata surya materi yang menarik,

b. media gambar dapat memberikan pemahaman kepada siswa.

c. faktor pendukung: motivasi dalam diri siswa,bimbingan orang tua.

d. faktor penghambat: kurangnya manajemen waktu, keadaan rumah yang tidak kondusif, sebagaian siswa masih terkendala akses internet,

e. kelebihan: lebih efektif, siswa dapat belajar secara mandiri,

f. kekurangan: tidak ada praktikum pada materi tata surya

3. Persepsi guru terhadap pelaksanaan pembelajaran google classroom era pandemic COVID-19 materi $x$ yaitu:

a. media yang paling efektif digunakan video

b. hasil belajar siswa masih rendah,

c. metode tanya jawab hanya $50 \%$ siswa yang aktif,

d. faktor penghambat: siswa belum siap dalam pembelajaran digital 
e. faktor pendukung: siswa tertarik untuk mengikuti pembelajaran karena menjadi hal yang baru bagi siswa,

f. kelebihan: efektif

g. kekurangan: pemahaman siswa terhadap materi akan berbeda ketika tatap muka secara langsung sebagaimana di gedung sekolah, dan kedisiplinan siswa masih kurang.

\section{Daftar Pustaka}

Agung Tri Wibowo, Isa Akhlis, Sunyoto Eko Nugroho. (2014). Pengembangan LMS

(Learning Management System) Berbasis Web untuk Mengukur Pemahaman Konsep dan Karakter Siswa. Scientific Journal of Informatics. Vol.

5(2): 726-739. https://journal.unnes.ac.id/nju/index.php/sji/article/view/4019

Handani, S. W., Suyanto, M., \& Sofyan, A. F. (2016). PENERAPAN KONSEP GAMIFIKASI PADA E-LEARNING UNTUK PEMBELAJARAN ANIMASI 3 DIMENSI. Telematika. https://doi.org/10.35671/telematika.v9i1.413

Herlawati, Handayanto, R. T., \& Solikin. (2018). Neural network regression with support vector regression for land-use growth prediction. Proceedings of the 3rd International Conference on Informatics and Computing, ICIC 2018. https://doi.org/10.1109/IAC.2018.8780475

Iskandar, dkk. (2020). Aplikasi Pembelajaran Berbasis TIK. Yayasan Kita Menulis.

Isnaini, M., Kusuma, D., \& Noviani, L. (2015). PENGARUH KOMPETENSI DOSEN DAN FASILITAS BELAJAR TERHADAP KEPUASAN MAHASISWA PENDIDIKAN EKONOMI FKIP UNS. BISE: Jurnal Pendidikan Bisnis Dan Ekonomi, 1(2), 1-20. https://doi.org/10.20961/BISE.V112.17968

Lexy J. Moleong, D. M. A. (2013). Metodologi Penelitian Kualitatif. ROSDA.

Prof. Dr. Sugiyono. (2016). Metode Penelitian Kuantitatif, Kualitatif, dan R\&D (Prof. Dr. Sugiyono (ed.); Cetakan ke). Alfabeta, bandung. http://scholar.google.com/scholar?cluster=10328650190657588078\&hl=en\&oi=scholarr Sunyoto, D. (2016). Metodologi Penelitian Akuntansi. REFIKA ADITAMA.

Udin Syaefudin Sa'ud. (2010). Inovasi Pendidikan (3rd ed.). Alfabeta.

Wikipedia bahasa Indonesia. (2020). Google Classroom. Wikipedia. https://id.wikipedia.org/wiki/Google_Kelas 